\title{
1958 y después: la radicalización temprana del movimiento estudiantil reformista. Una reconstrucción para la ciudad de La Plata, Argentina
}

\section{8 and after: The early radicalization of the reformist student movement. A reconstruction for the La Plata city, Argentina}

\author{
Nayla Pis Diez*
}

Resumen: El tema central de este trabajo son los procesos concretos de ruptura y renovación que se derivan del impacto de la "traición Frondizi" en el movimiento estudiantil reformista de la Universidad Nacional de La Plata (UNLP). En particular, aquí se indaga en dos caminos que tomaron los reformistas frondizistas: el ingreso a la trotskista Palabra Obrera y a MIR-Praxis. Se buscará reconstruir aquellas trayectorias atendiendo tanto a las razones que dieron lugar a tales movimientos como a sus consecuencias políticas y organizativas.

Palabras clave: Movimiento estudiantil, Radicalización, Palabra Obrera, MIR-Praxis, La Plata

\begin{abstract}
The central theme of this paper are the specific processes of rupture and renewal that arose from the impact of 'betrayal Frondizi' in the reformist student movement of the National University of La Plata. In particular, it explores two ways which the reformist frondizistas took: entering the trotskyist Palabra Obrera, and MIRPraxis. It will seek to reconstruct those trajectories taking care not only of the reasons that gave place to such movements but of the political and organizational consequences.
\end{abstract}

Keywords: Student movement, Radicalization, Palabra Obrera, MIR-Praxis, La Plata

Recibido: 5 mayo 2017

Aceptado: 28 julio 2017

\footnotetext{
* Argentina. Licenciada en Sociología por la Universidad Nacional de La Plata y docente en la misma institución. Becaria doctoral de la Comisión Nacional de Investigaciones Científicas y Técnicas (CONICET) con sede laboral en el Centro de Investigaciones Socio Históricas/Instituto de Investigaciones en Humanidades y Ciencias Sociales (CISH/IdIHCS) radicado en la mencionada universidad. Contacto: nayla.pdiez@gmail.com
} 


\section{Introducción}

El año 1959 no fue uno fácil para el movimiento estudiantil de las universidades argentinas. Pocos meses atrás, había sido protagonista de una de las protestas más importantes en su historia, aquella conocida como "Laica o Libre", contraria a la normativa que iría a permitir a universidades privadas y confesionales emitir títulos habilitantes para el ejercicio profesional, potestad hasta entonces bajo monopolio estatal. Estudiantes universitarios y secundarios de todo el país, agrupados en torno a la defensa de las banderas de la Reforma Universitaria ${ }^{1}$ y del carácter laico de la educación pública, se alzaron contra la normativa que, no obstante la amplia oposición, fue aprobada en octubre de 1958. Tal desenlace abrió una nueva etapa en la historia de los jóvenes universitarios de Argentina, marcada por rupturas y experiencias de radicalización que cuestionaron y renovaron su identidad política predominante, el reformismo. En este trabajo vamos a reconstruir dichas rupturas a partir del caso del movimiento estudiantil de la ciudad de La Plata (capital de la Provincia de Buenos Aires), cuya historia y actividad es tan relevante como poco explorada. Aquí se encuentra la Universidad Nacional de La Plata (UNLP), una de las más importantes del país junto a las de Buenos Aires y Córdoba, que cuenta además con un movimiento estudiantil de enorme tradición de lucha, con gran influencia y relación con el mapa nacional pero también con particularidades propias de una ciudad cuya política está marcada por la actividad y la dinámica universitarias.

Volviendo a los últimos años cincuenta, cabe decir que los procesos abiertos tras 1958 adquieren, para el estudiantado reformista de La Plata, ribetes propios aún no considerados por los estudios especializados. Por caso, en febrero de 1959 una docena de jóvenes de la Unión Cívica Radical Intransigente (UCRI), partido por entonces gobernante, decidió renunciar a la orgánica del mismo e ingresar a una organización novedosa, el Movimiento de Izquierda Revolucionaria (MIR)-Praxis. Casi todos los firmantes también eran conocidos militantes de agrupaciones reformistas. Por otro lado, en abril del mismo año, se anunció la creación del Centro de Estudios Sociales "Primero de Mayo", también integrado por dirigentes del reformismo universitario atravesados, según sus palabras, por la desesperanza y el desconcierto. Para comprender esta situación, es necesario remitirse a unos años atrás. A fines de 1955, buena parte los universitarios reformistas apoyó el golpe

1 Cuando se habla de movimiento estudiantil en Argentina, es imposible no remitirse a uno de sus hechos fundacionales, la Reforma Universitaria de 1918. Esta fue, en principio, un acontecimiento puntual que transformó las Universidades argentinas y latinoamericanas en función de un proyecto de gestión universitaria, basado tanto en la democratización política de sus órganos de gobierno, en la libertad de cátedra y en la renovación pedagógica y modernización curricular. Al mismo tiempo, la Reforma se constituyó en el programa político de la juventud universitaria latinoamericana de buena parte del siglo XX, con base en principios antiimperialistas, anticlericales, antioligárquicos y humanistas. Ver: Sigal, Intelectuales y poder en la década del sesenta,Buenos Aires, Puntosur, 1991; Portantiero Juan Carlos, Estudiantes y política en América Latina, 1918-1978, México, Siglo XXI, 1978. No obstante estas cuestiones generales, no hace justicia a la historia observar en el movimiento reformista un todo homogéneo. Contrariamente, la relación y el peso entre las cuestiones estrictamente universitarias, las políticas y partidarias, las relativas a la política latinoamericana e internacional, serán objeto de polémicas y disputas clave durante todo el siglo XX. 
de Estado que derrocó a Juan D. Perón ubicándose, en continuidad con la década anterior, en una posición de fuerte antiperonismo. Hacia mediados de 1956, tal férrea posición comienza a matizarse, así como el apoyo al régimen militar autodenominado como "Revolución Libertadora". Ya profundizaremos en esto, aquí solo cabe decir que, en este proceso de cambios, el lugar político que ocupó el radical Arturo Frondizi fue clave pues su figura concentró las críticas hacia el gobierno militar, articulándola con una propuesta nacionalista en términos económicos e "integracionista" hacia el movimiento peronista. Una parte importante de los jóvenes universitarios, del país todo y de La Plata, volcaron su apoyo hacia ese proyecto durante buena parte de 1957 y 1958, para encontrarse "frustrados" en poco menos de un año de gobierno. Una coyuntura atravesada por el conflicto social no hará más que ejercer presión sobre el mapa estudiantil. La mencionada "Laica o Libre" y las polémicas en torno a la introducción de capitales extranjeros en la explotación del petróleo colocaron a quienes habían apoyado la propuesta de Frondizi, en una situación de "traición”, “desconcierto" y búsqueda de nuevas opciones políticas.

Esta investigación busca aportar a los estudios sobre la historia reciente de Argentina, particularmente, de los años que van entre las décadas de 1950 y 1970, desde el abordaje de un actor en particular, el movimiento estudiantil. Son numerosos los trabajos que nos permiten caracterizar el período abierto a partir del golpe de Estado de 1955 como uno en que primó la inestabilidad política, la conflictividad social y un creciente desapego de la sociedad hacia las instituciones del sistema democrático liberal. En este contexto, la sociedad se fue volviendo más desafiante en sus demandas y sus métodos de acción ${ }^{2}$. El movimiento estudiantil no permaneció ajeno a dicho proceso, al contrario, fue protagonista tanto de la renovación ideológica como de la radicalización política que no dejó indemnes a las tradiciones políticas militantes de nuestro país. Desde aquí entendemos que para comprender cabalmente aquellas cuestiones no sirve ubicarse en los comienzos de la década de 1970, cuando ya eran evidentes las transformaciones marcadas, así como su masividad. Situándonos en 1958, una tesis central de este trabajo encuentra en dicha coyuntura una fecha clave para comprender las raíces del proceso de radicalización política que atravesó a una parte del movimiento universitario reformista a fines de la década del sesenta. Ya algunos trabajos clásicos han indagado en las consecuencias de la denominada "traición Frondizi" para el campo cultural e intelectual y para la militancia joven de los partidos Socialista (PS) y Comunista (PC). Desde los estudios sobre movimiento estudiantil, 1958 y la "traición" son bien señalados como una vía para la radicalización de posturas así como también, para el caso del reformismo de Córdoba, un momento clave de

2 Portantiero Juan Carlos, "Economía y política en la crisis argentina (1958-1973)", en Ansaldi y Moreno (comps.) Estado y Sociedad en el Pensamiento nacional, Buenos Aires, Cántaro, 1989, pp. 301-346; Pucciarelli Alfredo, "Los dilemas irresueltos en la historia reciente de la Argentina", en El Taller 4. Buenos Aires, 1997, pp. 82-121; O'Donnell Guillermo, "Estado y alianzas en la política argentina 1956-1976" en Desarrollo Económico 64, Buenos Aires, 1977, pp. 523-554; Tortti, María Cristina, "La nueva izquierda argentina. La cuestión del peronismo y el tema de la revolución" en Tortti (dir.) La nueva izquierda argentina (1955-1976), Socialismo, peronismo y revolución, Rosario, Prohistoria, 2014, pp. 15-33. 
encuentro con el movimiento obrero ${ }^{3}$. En sintonía, los dos casos aquí trabajados muestran representan gérmenes de ideas, proyectos y organizaciones que una década después actuarán con una masividad y adhesión ineludibles.

Finalmente, cabe decir que este trabajo encuentra un cimiento fundamental en las fuentes orales y en la documentación escrita utilizada. Las primeras son entrevistas realizadas por la autora y testimonios ya publicados por los protagonistas o en compilaciones amplias. En el segundo caso, particularmente, han sido de enorme utilidad registros de diarios locales con detallada y abundante información sobre la UNLP; y publicaciones estudiantiles que encontramos en el Archivo Personal de Ramón Torres Molina, gentilmente cedido a la autora. También ha sido fundamental el acceso al Archivo de la Fundación Pluma así como también a los documentos de espionaje elaborados por la Dirección de Inteligencia de la Policía de Buenos Aires (DIPBA) y hoy desclasificados por la Comisión por la Memoria (CPM).

\section{Los antecedentes y el contexto: la política nacional y las transformaciones en el movimiento estudiantil platense en 1956-1958}

Para cualquier trabajo que se proponga investigar procesos y actores políticos en la Argentina reciente, la coyuntura de 1955 es insoslayable. El movimiento militar que derrocó al gobierno de Perón e instauró un régimen bajo control de las Fuerzas Armadas, con apoyo cívico y eclesial, abrió una nueva etapa en la historia política y económica del país. En las universidades en particular, inauguró un período de desperonización y "refundación" realizados por organizaciones estudiantiles, profesores y graduados identificados con las banderas de la Reforma Universitaria y un fuerte antiperonismo ${ }^{4}$. Ahora bien, mediando 1956 se abre un nuevo ciclo que resulta clave para este trabajo pues aquel escenario inicial comienza a modificarse, tanto en La Plata como en el mapa del movimiento estudiantil nacional. Las grietas en dicho escenario surgieron al calor de las disonancias que generó la sanción del Decreto-Ley n6.043/55 (de Organización de las Universidades Nacionales), y en particular, su Artículo n²8 que permitía a las llamadas universidades "libres", privadas y/o confesionales, emitir títulos habilitantes para el ejercicio profesional. Durante mayo de 1956, las universidades y no pocos colegios

\footnotetext{
3 Terán Oscar, Nuestros años sesentas, Buenos Aires, Siglo XXI, 2013, p. 175 y ss.; Tortti María Cristina, "Debates y rupturas en los Partidos Comunista y Socialista durante el frondizismo", Prisma 6, 2002, pp. 265-274; Gordillo Mónica, "Protesta, rebelión y movilización: de la resistencia a la lucha armada, 19551973”, en James Daniel (comp.), Nueva historia argentina: Violencia, proscripción y autoritarismo 19551976, Buenos Aires, Sudamericana, 2003; Califa Juan, Reforma o Revolución. La radicalización política del movimiento estudiantil de la UBA 1943-1966, Buenos Aires, Eudeba, 2014; Ferrero Roberto, Historia crítica del movimiento estudiantil de Córdoba. Tomo III (1955-1973), Córdoba, Alción, 2009, p. 98.

${ }^{4}$ En la UNLP pasados los primeros días del golpe, la Universidad y todas las facultades fueron ocupadas bajo un espíritu general de festejos y triunfo. En los discursos de profesores y estudiantes sobresalía una posición de corte liberal democrático, de fuerte énfasis en la defensa de las libertades políticas y la participación democrática, que bien se amalgamó con la reivindicación de los principios reformistas, los mismos que, tras septiembre de 1955, vendrían a asegurar aquellas libertades en el ámbito universitario.
} 
secundarios del país se encontraron en estado de ebullición al tiempo que, en La Plata, sus estudiantes ocuparon seis colegios secundarios, el Rectorado, ocho facultades y fue establecida en la UNLP una Junta de Gobierno estudiantil. Aunque el artículo no fue aprobado, el conflicto dejó una serie de consecuencias importantes en el movimiento reformista. Por un lado, las expectativas hacia el gobierno militar comenzaron a matizarse al punto de que voces críticas ganaron paulatinamente lugar. Por otro lado, una fuerte crisis marcó al movimiento universitario platense, pues las protestas contra la normativa enfrentaron tanto a jóvenes cristianos con reformistas como también a reformistas entre sí, provocando renuncias y una intervención de la Federación Universitaria Argentina (FUA) por sobre la Federación de La Plata (FULP) por 60 días. En este marco, la FULP llamó a elecciones en todos sus Centros de Estudiantes, dando así inicio a un proceso de renovación de sus dirigencias que se cruzó con otro más bien político-partidario como fue el surgimiento de grupos estudiantiles alineados con la fracción Intransigente de la Unión Cívica Radical (UCR) liderada por Arturo Frondizi. Este, uno de los partidos con mayor influencia en el ámbito universitario, atravesaba también un fuerte proceso de fracturas, entre otras cosas, por el posicionamiento a adoptar frente al régimen militar gobernante5.

La composición política del reformismo platense comenzaba a cambiar. Entre 1955 y 1956 encontramos un mapa dominado por una alianza entre militantes y núcleos cercanos a la UCR y grupos socialistas y anarquistas, unidos tanto por su ferviente antiperonismo como por el propósito de hacer frente a los grupos comunistas, generalmente, minoritarios. La hegemonía de esta alianza se expresó a través de su fuerza en Facultades clave como son Derecho, Ingeniería y Medicina, y tanto en la FULP como en la delegación platense a la FUA encabezada por Norberto Rajneri, su presidente hasta mayo de 1956. Este mapa cambia a fines de 1956 a través de aquel proceso de renovación que mencionamos, traducido además en el surgimiento de núcleos universitarios identificados con el ala Intransigente de la UCR. A partir de aquí las iniciativas de la nueva gestión de la FULP comenzaron a delimitar una orientación dada por la emergencia de posturas críticas al gobierno de la "Revolución Libertadora" y un moderado acercamiento al movimiento obrero acompañado de fuertes críticas a la pérdida de derechos sociales y políticos de dicho sujeto. Al mismo tiempo, ese conjunto de elementos va a marcar una divergencia cada vez más clara en el seno del reformismo entre quienes, revisando sus posiciones iniciales, van a distanciarse de las políticas oficialistas y quienes no realizarán revisión de ningún tipo.

\footnotetext{
$5 \quad$ En noviembre de 1956 la Unión Cívica Radical finalmente se dividió. Las razones de tal desenlace fueron dos: primero, qué postura asumir frente al peronismo proscripto; y segundo, cuál ante el gobierno de Aramburu y centralmente, su gestión económica. Las siglas UCR del Pueblo (UCRP) y UCR Intransigente (UCRI) bautizaron respectivamente a quienes mantuvieron una férrea postura tan antiperonista como "optimista" respecto de la Revolución Libertadora; y al grupo liderado por Arturo Frondizi, con un antiperonismo cada vez más "tolerante" hacia el espacio derrocado, tal como ha dicho María Estela Spinelli, y crítica hacia la "Revolución Libertadora". Según la misma autora, la UCRI y la figura de Frondizi intentaron constituirse como un espacio superador de la dicotomía peronismo/antiperonismo, colocando el énfasis no tanto en las críticas a una supuesta dirigencia "nazi fascista" sino más bien en la adhesión que el peronismo había logrado en las masas populares. La lectura del peronismo como un fenómeno político de masas ya ineludible conllevaba la necesidad de interpelarlo políticamente. Ver Spinelli María Estela, Los vencedores vencidos. El antiperonismo y la "revolución libertadora”, Buenos Aires, Biblos, 2005.
} 
Avanzada Reformista de Derecho y Agrupación Reformista de Estudiantes de Ingeniería (AREI) fueron, en las facultades con mayor población, las agrupaciones que iniciaron aquel desplazamiento, cuya composición fue una mayoritariamente alineada con aquella opción partidaria. También fueron importantes A-18 de Arquitectura, Agrupación Reformista Independiente de Ciencias Económicas (ARICE) y el grupo Estudiantes Reformistas (ER) de Humanidades.

La llegada a la presidencia de Arturo Frondizi es otro acontecimiento clave para nuestra historia. Como han afirmado importantes estudios, su campaña electoral, primero, y luego su victoria en febrero de 1958, generaron hondas expectativas en intelectuales, profesionales y estudiantes cercanos al mundo de la izquierda pero atravesados por una suerte de crisis política e ideológica6. Según Carlos Altamirano dicha crisis encontró expresión en una suerte de fractura generacional en los mayores partidos de izquierda, que incluyó una "situación revisionista" respecto del fenómeno peronista, antecedida por una "crisis ideológica" en el seno de una juventud atravesada por la culpa por los lugares políticos que ocupó en la historia argentina ${ }^{7}$. A esto, agrega Silvia Sigal que, pasado el año 1955, la persistencia de la identidad peronista en los sectores populares así como la política represiva de la "Revolución Libertadora" actuaron introduciendo grietas en las posturas antiperonistas de los jóvenes universitarios y militantes de izquierda ${ }^{8}$. El frondizismo, expuesto como frente "nacional y popular", y su propuesta de "integración" hacia el movimiento obrero peronista, colaboraron con la resolución política de dicha crisis.

Considerando este marco, se explica mejor el ascenso del espacio frondizista en el reformismo universitario de la UNLP entre 1956 y 1957. Las posiciones críticas hacia el régimen militar inaugurado en 1955, se tradujeron en una serie de elementos que cabe ordenar. Por un lado, tales críticas se centraban en la pérdida de derechos sociales y en la política represiva aplicada sobre el movimiento obrero. No fueron pocas las acciones de la FULP que, durante todo 1957, se colocaron en solidaridad con dicho actor, denunciando además a un gobierno que se entendía "peor que el anterior" en materia de respeto de los derechos y la democracia ${ }^{9}$. De tales críticas se desprende, además, un abandono de las

6 Sin embargo, cabe decir que buena parte del triunfo se debió al apoyo peronista, obtenido tras haber "pactado" con Perón el levantamiento de la proscripción, el restablecimiento de la legislación laboral suspendida y la "devolución" de la Confederación General del Trabajo (CGT) intervenida desde 1955. Una buena reconstrucción del plan desarrollista y sus consecuencias en: Belini Claudio y Korol Juan Carlos, Historia económica de la Argentina en el siglo XX, Buenos Aires, Siglo XXI, 2012, pp. 162-170.

$7 \quad$ Altamirano Carlos, Peronismo y cultura de izquierda, Buenos Aires, Temas Grupo Editorial, 2001

$8 \quad$ Sigal, Intelectuales y poder en la década del sesenta, Buenos Aires, Puntosur, 1991, p.144. En el campo intelectual, la revista Contorno, dirigida por los hermanos Viñas, se ha señalado como ejemplo de este tipo de trayectorias y desplazamientos: jóvenes que rompían con sus "maestros", anunciaban el fracaso político de una generación militante (la "generación del cuarenta y cinco" constituida en base a la oposición a los gobiernos peronistas) y proponían ensayar nuevas recetas políticas en el frondizismo.

$9 \quad$ En enero de 1957, en un acto realizado en Ensenada por estudiantes y obreros se afirmaba que "el actual gobierno es peor que el anterior" pues el actual "no solo utiliza los métodos del otro, sino que los ha superado en cuanto a materia de persecución refiere". En este marco, el presidente del Centro de Estudiantes de Ingeniería, de AREI, afirmó que "La llamada democracia propiciada por el actual gobierno era un mito, como asimismo la libertad. Prueba evidente de ello son (...) los inocentes encarcelados, trabajadores asesinados y el hambre y la miseria que amenaza cernirse sobre los hogares de los trabajadores". En: 
posiciones antiperonistas que, de acuerdo con la propuesta de la UCRI, priorizaba el acercamiento a las bases obreras peronistas en pie de lucha contra el régimen gobernante. Por otro lado, el latinoamericanismo, un principio clásico del reformismo que, abandonado durante la década anterior frente a posicionamientos internacionales de corte antifascista y de defensa de la democracia liberal, comenzó a adquirir un contenido concreto antiimperialista y, más concreto aún, crítico hacia la política estadounidense en la región. Por último, este sector reformista va a iniciar una suerte de abandono de las posturas más anticomunistas, también heredadas de la década pasada. El entonces dirigente estudiantil Julio Godio, reconoce que, hacia fines de 1956 y hasta comienzos de 1959, el predominio en la política estudiantil de La Plata pasó a estar en la militancia reformista identificada con la UCRI ${ }^{10}$. Lo que él denomina "el frondizismo universitario", se mantuvo y creció en coalición con la militancia universitaria del Partido Comunista (PC), fuerte en facultades como Humanidades y Derecho, y núcleos independientes, dando lugar así a una suerte de corriente reformista de izquierdas. Además de las agrupaciones mencionadas, algunos de sus referentes más importantes fueron Alejandro Dabat y Ramón Torres Molina de Avanzada Reformista, Mario Marcovich y Carlos Schiavello de AREI de Ingeniería, Adolfo Sturzenegger de ARICE de Económicas, Julio Godio de ER de Humanidades.

\section{8: Universidades y “entrega nacional”. El año del desencanto}

En La Plata, el año 1958 ya comenzó tumultuoso para los universitarios. En el marco del anuncio de la creación de la Universidad Católica de Buenos Aires, a comienzos de marzo, adquirió fuerza pública el debate en torno no solo a la existencia de universidades privadas; también, y tempranamente, se puso sobre la mesa la problemática relación entre universidades, educación y soberanía nacional. Frente a tamaña noticia, por ejemplo, la FULP va a manifestar su repudio declarando el hecho una "ofensiva oligárquico imperialista" y una "agudización del carácter clasista de la educación"11. El año 1958 se había iniciado con una problemática que iría a marcar el año para los estudiantes: el avance del "elitismo" y de las "fuerzas reaccionarias" en la educación.

Documento Movimiento de Solidaridad obrero estudiantil, CPM-Fondo DIPBA, Mesa A, Carpeta Estudiantil, Leg. 22. En 1957, al igual que ocurría en un plano nacional, el mundo sindical platense se encontraba dividido en dos grupos, los sindicatos "libres" y los cohesionados en la Comisión Intersindical (independientes, comunistas y peronistas). Dentro de este heterogéneo grupo, los gremios comunistas e independientes fueron los más dispuestos a la coordinación con el movimiento estudiantil.

10 Toer Mario, El movimiento estudiantil de Perón a Alfonsín, Buenos Aires, CEAL, 1988, pp. 100101.

11 El Argentino, 25/03/1958. Continúa la declaración de FULP al respecto: "Que la Universidad que acaba de fundarse configura, en cuanto pretende otorgar títulos habilitantes, un problema educativo, político y social, y nunca religioso. Su discusión nada tiene que ver con el derecho de enseñar y aprender (...) sino que está estrechamente ligado a criterios de soberanía nacional y progreso social. Que en ese sentido su fundación puede ser considerada como el punto de avanzada de toda una ofensiva oligárquico imperialista sobre nuestra educación (...)". Luego, un poco más adelante y frente a una asamblea de 300 estudiantes, Alejandro Dabat, en representación de la FULP, manifestó su apoyo denunciando el "plan reaccionario que pretende limitar la Universidad a su viejo papel de formación de élite" (El Argentino, 27/05/1958). 
La asunción efectiva de Arturo Frondizi, que tuvo su lugar en el mes de mayo, modificó inicialmente aquel panorama. En principio y durante el primer tramo de su gobierno, "los ocho meses desarrollistas", Frondizi tomó una serie de medidas que cumplían buena parte de sus compromisos con el movimiento obrero y el peronismo, entre ellas, una amplia amnistía y la sanción de la Ley de Asociaciones Profesionales mermando así los conflictos estrictamente obreros durante estos primeros meses ${ }^{12}$. Sin embargo, la segunda mitad de 1958 va a estar marcada por importantes conflictos en torno a la privatización de ámbitos estatales que, en el lenguaje de la época fue leído como "entrega" de las empresas nacionales, el petróleo y la educación. En particular, un repudio generalizado provocó el remate de casi treinta empresas pertenecientes a la Dirección Nacional de Industrias del Estado (DINIE); repudio que se manifestó en la movilización de sus trabajadores, la oposición de importantes partidos políticos y su tratamiento en el Congreso durante el mes de julio ${ }^{13}$. Ni los reformistas platenses, ni la FUA, quedaron por fuera de dicho clima, afirmando incluso su oposición a la venta de empresas al imperialismo y los capitales privados ${ }^{14}$. Dadas las cosas, debe apuntarse que los temas del estudiantado estaban comenzando a articularse a partir de una lectura que ubicaba temas propios del campo universitario (el "limitacionismo", el elitismo o la creación de universidades privadas) en el contexto más general de oposición a la "entrega del país" y de "avance de fuerzas reaccionarias", el clero, la oligarquía y el imperialismo. El comunicado ante el aniversario de la Reforma de la FULP, de junio de 1958, dice sobre la situación del país y el movimiento obrero:

“(...) Que libra en este instante la difícil batalla de la unidad contra diversos factores disociadores, instándolo a la lucha en común contra las fuerzas del privilegio atrincheradas en los centros del poder económico (...) Hoy, sin embargo, otras son las circunstancias. La regresión cambia de táctica: funda Universidades privadas, trabaja en las universidades nacionales para impedir el acceso del pueblo y trata de facilitar la penetración imperialista." 15

12 Sobre 1958 y la relación entre las jefaturas sindicales y Frondizi, ver: James Daniel, Resistencia e integración, Buenos Aires, Siglo XXI, 2010, pp. 147-157; Schneider Alejandro, Los compañeros: izquierda, trabajadores y peronismo en la Argentina, 1955-1973, Buenos Aires, Imago Mundi, 2005, pp. 113-120.

13 Luego de paros y manifestaciones de los trabajadores de las empresas y un acalorado debate en el Congreso, casi treinta empresas DINIE (farmacéuticas, textiles, metalúrgicas, eléctricas, entre otras ramas) fueron rematadas, alegando la importancia de los compromisos internacionales asumidos y la necesidad de fortalecer la seguridad jurídica del país. Ver: Belini Claudio, "Reestructurando el estado industrial: El caso de la privatización de la DiNIE, 1955-1962”, Desarrollo Económico 181, abril-junio 2006, pp. 89-116.

14 Por ejemplo, los Centros de Derecho y Química y Farmacia se manifestaron en contra con un discurso antiimperialista similar al que va a marcar los meses siguientes. El segundo dijo al respecto: "El país ha contemplado con dolor el remate (...) Los obreros de las empresas DINIE, los estudiantes de todo el país, importantes sectores gremiales y políticos, que conforman la inmensa mayoría del pueblo, se habían pronunciado contra la entrega de las empresas (...) El Centro de Estudiantes eleva su enérgica protesta por la entrega de las empresas y está dispuesto a bregar firmemente para que el núcleo restante de las DINIE no sea entregado a capitales privados" (El Argentino, 18/07/1958).

15 El Argentino, 15/06/1958. 
Durante el mes de agosto, las movilizaciones por la "cuestión petrolera" marcaron la agenda estudiantil de la misma manera. En julio, un discurso del mismo Arturo Frondizi había anunciado la entrada de capitales extranjeros para la exploración y explotación de yacimientos nacionales de hidrocarburos. La oposición de amplios sectores contra la denominada "Batalla del Petróleo", comenzó a marcar el escenario político del país con la movilización obrera en su contra y una repuesta gubernamental cada vez más represiva. En La Plata, dicha oposición incluyó tanto al movimiento reformista como también a buena parte de las fuerzas sociales y políticas de la ciudad, configurando un amplio movimiento de acción ${ }^{16}$. Prácticamente en simultáneo, estalló la "Laica o Libre", esto es, el conflicto en torno a la reglamentación de aquel Artículo n ${ }^{\circ} 28$ postergado en 1956 que daba mayor jerarquía a las universidades no estatales, denominadas entonces "libres". De proporciones conocidas, este acontecimiento es una suerte de parteaguas en nuestra historia: nos indica el cierre del ciclo de ascenso de frondizismo y, al mismo tiempo, el comienzo de su fragmentación y crisis.

Aunque no vamos a realizar una cronología pormenorizada del conflicto sí nos interesa dejar sentadas algunos elementos que nos ayudan a comprender tanto el significado de 1958 como sus saldos políticos para los jóvenes de la UNLP ${ }^{17}$. Considerando el plano de las acciones, podemos decir que entre los meses de agosto de 1958 y marzo de 1959, la ciudad de La Plata se vio atravesada por movilizaciones callejeras, diversos formatos de acción directa y enfrentamientos entre fuerzas estudiantiles que no solían terminar de la mejor manera. Entre los meses de septiembre y octubre visualizamos un claro ascenso en la dinámica del conflicto, dado por el posible tratamiento en el Congreso Nacional del tema. Durante esos días se realizaron poco más de quince actos en la ciudad, la mitad de ellos implicó choques entre las organizaciones cristianas y las reformistas y entre estos últimos con las fuerzas policiales, con golpes, cascotazos, gases lacrimógenos y armas de fuego de por medio. La mayor parte de esos actos fue seguida por ataques a diversos representantes del poder político y mediático: las sedes de los principales diarios, los edificios gubernamentales y las oficinas y ministerios del poder represivo; también, las Iglesias y las

16 Por ejemplo, los primeros días de agosto la FULP organizó una mesa redonda bajo el nombre "El plan petrolero del gobierno" que contó con la presencia de Silvio Frondizi, Daniel Alvarado (delegado del Sindicato de Petroleros del Estado) y profesores de Ingeniería y Derecho (El Argentino, 8/08/1958). Los contratos petroleros obtuvieron el repudio de buena parte de las organizaciones estudiantiles, entre ellas, por ejemplo, el Centro de Estudiantes de Ingeniería, conducido por AREI, los va a considerar una "intromisión del imperialismo en los países latinoamericanos" (El Argentino, 12/09/1958). Por otra parte, un comunicado de Lista Violeta, agrupación comunista de Derecho afirmaba: "En concordancia y haciendo suyos los fundamentos del SUPE declara: que deben rechazarse por lesivos para los intereses de la Nación y el pueblo, los acuerdos realizados con capitales monopolistas extranjeros; que es necesaria la nacionalización integral del petróleo; que es deber del estudiantado luchar junto con todas las fuerzas populares para ganar la batalla del petróleo" (El Argentino, 10/08/1958).

17 La mayor parte de esta reconstrucción está basada en Pis Diez Nayla, "Es hora de jugar la Universidad. Una reconstrucción de las luchas reformistas en las calles platenses durante la Laica o Libre”, Conflicto Social 15, Buenos Aires, 2016. Para comprender la dimensión nacional de este conflicto ver Califa Juan, op. cit.; Manzano Valeria, "Las batallas de los "laicos": movilización estudiantil en Buenos Aires, 1958" en Boletín del Instituto de Historia Argentina y Americana “Dr. E. Ravignani” 31, Buenos Aires, 2006, pp. 123-150. 
escuelas religiosas de la ciudad. Pocos espacios de la ciudad escaparon a este conflicto que cotidianamente le imprimía su radicalidad. Más en particular, en las universidades, las asambleas y medidas de lucha fueron durante esos dos meses constantes. Se llegó, incluso, a realizar una semana entera de "huelga estudiantil" en los inicios del mes de octubre.

Mediando septiembre de 1958, y mientras los enfrentamientos estudiantiles con la policía eran moneda corriente en La Plata, una delegación de FULP asistió al plenario de la CGT regional para solicitar apoyo obrero consiguiendo que la entidad, neutral en un inicio, tomara una postura favorable a su lucha. A los pocos días, la FULP expresó su adhesión a un paro total convocado por la misma entidad obrera para el 10 de octubre; en esta ocasión no ahorró palabras para expresar la importancia estratégica de dicha alianza:

"El estudiantado no puede menos que solidarizarse con quienes luchan por mantener sus conquistas y obtener un nivel de vida acorde a sus necesidades. La clase obrera encontrará siempre a su lado a la masa estudiantil que, ahora más que nunca, es consciente que solo esa unidad podrá encontrar la solución a los graves problemas que afligen al país." 18

Encontramos aquí una serie de elementos que nos hablan de un intento de mayor acercamiento entre ambos actores propiciado por los universitarios, para la oposición común a las medidas del gobierno frondizista. Tal acercamiento no se comprende sin colocar el ya mencionado alejamiento de la FULP respecto de posiciones antiperonistas, que se tradujo también, en una autocrítica y reconsideración respecto del peronismo como proceso histórico y como identidad política de los trabajadores. Este dato nos lleva a resaltar un elemento poco asociado a este período como son las iniciativas estudiantiles por articular sus acciones con un movimiento obrero cada vez más enfrentado al gobierno de Frondizi, orientación más asociada a las insurrecciones populares de los años 1968 y 1969 pero, como vemos, presentes ya en 1957 y 1958. Más allá de las limitaciones y del distinto grado de éxito alcanzado, el intento de establecer dicha alianza formó parte del repertorio de acciones de los estudiantes movilizados de buena parte del país (La Plata, Ciudad de Buenos Aires, Mar del Plata, Rosario y Santa Fe, Córdoba)19.

$\mathrm{Si}$ arriba consideramos el plano de las acciones, no menos importante es el de los discursos, las posiciones e interpretaciones en torno al conflicto. Esta dimensión nos permite señalar, primero, qué estaba en juego para los estudiantes en dicho conflicto; pero también, dar cuenta de qué posiciones y críticas comenzaron a hacerse visibles hacia un gobierno que en principio se apoyaba. En primer lugar, buena parte de las posiciones

$18 \quad$ El Argentino, 4/10/1958.

19 Para profundizar en la temprana relación del movimiento estudiantil con el movimiento obrero (peronista y no) vale la pena ver: Bartolucci Mónica, "La primavera del 58. Revueltas, tomas y bataholas juveniles durante el conflicto "Laica o Libre" en Mar del Plata", Historia Política, 2008; Ferrero Roberto, op.cit., pp. 98. Para el caso platense, Pis Diez Nayla, "Compañero trabajador, no falte! El movimiento reformista de La Plata y la unidad obrero-estudiantil en los tempranos sesenta: acciones por una vieja bandera", Revista de la Red de Intercátedras de Historia de América Latina Contemporánea 6, 2017, pp. 99114. 
reformistas debatía con el mote de "libertad de enseñanza", elemento clave del proyecto de ley, que los estudiantes consideraron una falacia pues para ellos, no estaba en juego dicha libertad sino la posibilidad de crear universidades "al servicio" de los sectores dominantes. Los discursos ponían el énfasis en los intereses leídos como clasistas, extranjeros y reaccionarios que se ocultaban bajo el principio de la libertad. El integrante de ARICE y presidente del Centro de Estudiantes de Ciencias Económicas (A. Sturzenegger) fue, en su intervención frente a tres mil estudiantes, muy contundente al sostener que detrás de la creación de universidades privadas se encontraba el accionar de tres fuerzas sociales: "primero, de la financiación internacional e imperialismo; segundo, de la oligarquía y la burguesía industrial internacional; tercero, el alto clero" ${ }^{20}$. Con una perspectiva compartida ya el Centro de Estudiantes de Derecho, conducido por Avanzada Reformista, había hecho público su repudio “(...) A todo intento de imponer en el país el régimen de las universidades privadas, que no harán sino implantar el privilegio, favoreciendo mezquinos intereses que, como los del clero, la oligarquía y el imperialismo, pretenden dividir al pueblo" 21 . Este debate no era menor, al contrario, las movilizaciones laicas fueron caracterizadas por miembros del gobierno como "golpistas". Esto nos conduce a otra cuestión, la caracterización del gobierno que comenzó a esbozarse al calor del conflicto. Estos reformistas, otrora entusiastas del proyecto oficial, lo calificaron como principal responsable de la encendida situación que atravesaba el país repudiando sus decisiones tanto en el ámbito educativo como en el económico, energético y laboral. Con el correr de los días, el conflicto educativo comenzó a comprenderse en un plano más general, igual de repudiable, de "entrega" del país empalmando así con los debates en torno a la Batalla del Petróleo que marcaron los últimos meses de 1958. En noviembre de 1958, en Mendoza, una huelga del gremio petrolero en repudio a los contratos de explotación con empresas extranjeras fue declarada ilegal por el gobierno que, además, decretó el Estado de Sitio en todo el país y la proscripción del PC. A partir de aquí, el nivel de represión fue en aumento al tiempo que las medidas económicas gubernamentales irían a reducir los niveles de popularidad del ya cuestionado Arturo Frondizi ${ }^{22}$.

$20 \quad$ El Argentino, 9/09/1958.

$21 \quad$ El Argentino, 5/09/1958.

22 A fines de 1958 el gobierno presentó el Plan de Estabilización y Desarrollo. Condicionado a un acuerdo con el FMI, el Plan abarcaba medidas como la liberación del tipo de cambio y una fuerte devaluación; la liberación de los precios; la "reestructuración" de la administración y las empresas estatales (que incluía la posibilidad de privatizarlas); la igualdad de derechos entre el capital extranjero y el nacional. De su aplicación no podía sino derivarse un aumento de la protesta social, particularmente, en los sectores "reestructurados", ferroviarios, bancarios, petroleros. Sobre la conflictividad obrera en, por ejemplo, los ferroviarios ver Schneider Alejandro, op.cit., pp. 170 y ss.; sobre las medidas económicas, Belini Claudio y Korol Juan Carlos, op. cit., pp. 166-168. La aplicación de tales políticas estuvo acompañada por la intensificación de la represión y el anticomunismo. A partir del año 1959, se sucede la sanción de decretos y leyes que enfocaban el problema de la seguridad en clave de guerra interna antisubversiva. En marzo de 1960 es puesto en vigencia el más conocido Plan Conintes, que colocaba la seguridad interna en manos de las Fuerzas Armadas. Ver: Pontoriero Esteban, "Estado de excepción y contrainsurgencia: el plan Conintes y la militarización de la seguridad interna en la Argentina (1958-1962)", Contenciosa 4, primer semestre de 2015. 
En los discursos de los reformistas, entonces, universidad "libre" era más bien sinónimo de universidad "privada" y funcional a los intereses de la Iglesia, el imperialismo y la oligarquía, claros enemigos históricos del reformismo. La denuncia contra el gobierno, aparecía además como broche final: es que de un programa antioligárquico, popular y antiimperialista se había pasado en menos de un año a un gobierno que aparecía como pro clerical, pro imperialista y anti obrero. El desconcierto de quienes lo habían apoyado no era algo menor. A partir de aquí se inician en el seno del movimiento estudiantil reformista procesos de rupturas y deslizamientos claves para pensar la década siguiente. No tanto por su masividad, pues estamos hablando de pequeños grupos, sino por la fuerza y persistencia de sus ideales. De alguna manera, debemos pensar que no se comprende 1966 y lo que siguió sin 1958, las trayectorias ideológicas y militantes deben pensarse en este "largo plazo" sin el cual las opciones políticas parecen "brotes" irracionales o modas generacionales. En definitiva, colocados en el cierre de 1958, luego de un año de frustraciones para los jóvenes reformistas, nuevos debates y nuevas opciones acuciaban.

\section{1958 y después: rupturas en el reformismo universitario}

La lucha "Laica o Libre" continuó durante 1959, centrada en el repudio a la reglamentación de la Ley meses atrás aprobada. Los conflictos obreros se agudizaron, las huelgas bancarias y ferroviarias dieron el tono a un año que había comenzado con la emblemática toma del frigorífico "Lisandro de la Torre" contra su privatización. El año 1959 fue también aquel en el cual las consecuencias de 1958 se expresaron con claridad en el seno del movimiento estudiantil platense. Esto es, al desconcierto de 1958 le siguió la desarticulación del espacio mayoritario. En el lenguaje de la época, este proceso fue conocido con el mote de traición, la "traición Frondizi" con fuertes repercusiones entre los jóvenes intelectuales y los partidos de izquierda más importantes del país, tal como señalamos en un comienzo. Para el otrora militante comunista de Buenos Aires, Bernardo Kleiner, la derrota de 1958 derivó en un fuerte escepticismo para la mayoría de los dirigentes reformistas; en los grupos muy influidos por la UCRI, la traición del gobierno causó además una gran desorientación abriéndose así una etapa crítica para este sector ${ }^{23}$. A fines de la década de 1980, Julio Godio, también militante comunista de la UNLP, dio cuenta en sus palabras de la "decepción" y sus consecuencias políticas, "Naturalmente el resultado fue la decepción. Y sobre todo en lo jóvenes, la decepción genera generalmente cambios bruscos (...) Todo esto generó una crisis en el interior del movimiento estudiantil y el frondicismo perdió su base de apoyo."24.

La claridad de los protagonistas nos otorga pistas sobre lo que ocurrió tras la “traición Frondizi” entre los jóvenes reformistas platenses. Efectivamente, por un lado, nos encontramos con aquellos "cambios bruscos" visualizados por Godio pues buena parte de la militancia que ubicábamos como reformista de izquierdas, la cercana o militante de la

23 Kleiner Bernardo, 20 años de movimiento estudiantil reformista, Buenos Aires, Platina, 1964, pp. 227-228.

24 Toer Mario, op. cit., p.101. 
UCRI, entró en una suerte de crisis ideológica luego de 1958. La cada vez menor identificación con un proyecto ahora desmentido, tuvo como correlato el "desbande", es decir, la sangría de jóvenes militantes que optaron en la mayoría de los casos por opciones radicales $^{25}$. Las agrupaciones frondizistas entraron entonces en una suerte de crisis múltiple, ideológica, política y electoral, que se materializó en experiencias, individuales y grupales, de radicalización hacia la izquierda de sus referentes. Estas nuevas elecciones políticas se vieron acompañadas de fuertes críticas a la UCRI gobernante, al reformismo universitario, así como también a las formas de funcionar que la política argentina había asumido de 1955 en adelante. En concreto, las trayectorias de los "decepcionados" se inclinaron por dos caminos: la trotskista y más ligada al mundo obrero, que tuvo un derrotero no universitario; y la opción más bien novedosa dada por el surgimiento de núcleos ligados al MIR-Praxis, organización liderada por Silvio Frondizi, hermano del presidente.

En segundo lugar, el frondizismo universitario entró en crisis como espacio político. No solo perdiendo su base de apoyo, es decir, su caudal electoral; también, sus agrupaciones más fuertes sufrieron un proceso de fragmentación que a su vez, va a provocar aquellas pérdidas electorales que con el tiempo fueron cada vez mayores. Ni Avanzada Reformista de Derecho, ni AREI de Ingeniería o ARICE de Económicas se salvarán de ello. Entonces, pérdida de apoyo electoral y desintegración de sus espacios organizativos es el otro proceso que atraviesa al frondizismo universitario, junto a su desintegración ideológica. Una de las consecuencias directas de esto fue el crecimiento de las agrupaciones del comunismo, opción política que pasó a ocupar el espacio de izquierda vacante.

En síntesis, procesos de radicalización política, fragmentaciones organizativas y pérdida de caudal electoral, constituyen los procesos centrales que atravesaron a la corriente mayoritaria del reformismo platense durante 1959 provocando además una suerte de inestabilidad política en la conducción de la FULP que no se resolverá hasta mediados de 1960. A continuación, se presenta un análisis de cada uno que intenta concentrarse en aquellos dos planos de la crisis: el político-ideológico, es decir, qué críticas programáticas existían, qué lecturas de la política nacional y estudiantil y qué nuevas opciones se desprenden de ello; el político-organizativo, que pretende atender las características de los nuevos espacios creados, su fuerza real y sus lazos con el ámbito de la política partidaria.

25 La expresión pertenece a Héctor Palacios, de Avanzada Reformista: “(...) Hubo un desbande tremendo. En avanzada y en el movimiento estudiantil en la medida en que Frondizi fue no cumpliendo lo que había planteado. Sobre todo el hilo se cortó en septiembre u octubre cuando la huelga petrolera. Ya la lucha Laica o Libre se perdió porque evidentemente el gobierno, a pesar de las grandes movilizaciones, metió la Ley. Pero bueno, para nosotros, la experiencia o límite, para romper con el frondizismo fue esa (...) También cuando reprimieron la huelga petrolera y la militarizaron, ya eran anti-obreros. Entonces, la cuestión desembocó a fin del año 1958, principios de 1959, también cuando fue la huelga de enero del '59 en el Lisandro de la Torre. Ahí yo ya dije "No. Acá no va más", fui a verlo a Dabat y después nos fuimos todos. Ahí se divide mucho la cuestión y es un poco caótico porque nos desparramamos todos." (Entrevista realizada por la autora, 30/03/2017). 


\section{De la UCRI al MIR-Praxis: la "nueva izquierda" como espacio político de "los frustrados"}

Los primeros días de febrero del año 1959, un grupo de más de diez militantes de la Juventud de la UCRI platense declara su renuncia mediante un comunicado público aparecido en los grandes diarios de la ciudad $^{26}$. Una expresión cabal de lo que arriba denominamos como crisis ideológica y organizativa al mismo tiempo. En este caso, las críticas que el núcleo disidente presentó estuvieron orientadas tanto hacia el Radicalismo Intransigente como también hacia Avanzada Reformista, la agrupación que expresaba ese sector en la UNLP. Por esto, nos encontramos con argumentaciones y desplazamientos en los cuales se entremezclan las cuestiones política, universitaria y estudiantil reformista. Establecer las temporalidades ha resultado algo más fácil: en febrero, hace pública su disconformidad el núcleo orgánico de los jóvenes de la UCRI solicitando al mismo tiempo, el ingreso a MIR-Praxis. En mayo, los renunciantes de la solicitada que estudiaban en la facultad de Derecho anuncian su separación de Avanzada Reformista y el armado de un nuevo grupo, Izquierda Estudiantil Revolucionaria (IER) "brazo estudiantil” del MIRPraxis.

La ruptura de los jóvenes con la orgánica partidaria encuentra razones en dos elementos que se desprenden de sus análisis de la coyuntura argentina de 1958-1959. Por un lado, se manifiesta la evidencia de la "traición" al programa de la UCRI, al cual se le reconoce su sentido transformador y progresista, no obstante, abortado por la acción de un gobierno que, se entiende, acabó constituido en el "más eficiente servidor del imperialismo" con una orientación antiobrera y profundamente represiva. Por otro lado, aparece la conclusión política que posibilita el desplazamiento: el fracaso de la experiencia de la UCRI gobernante demuestra, para el grupo disidente, "la imposibilidad de realizar una transformación en la estructura del país" con un programa de tipo desarrollista ${ }^{27}$. Anunciando un debate clave para las izquierdas latinoamericanas de los años sesenta, el texto sugiere dos factores que constituyen aquella imposibilidad, la debilidad de la burguesía nacional y su dependencia respecto de Estados Unidos, principal centro imperialista. No solo la traición programática del frondizismo, sino también la certeza de que Argentina debía transformar su estructura capitalista (no solo su carácter dependiente), evidencian un desplazamiento hacia opciones de izquierda radicales de este grupo. El texto además manifestaba el ingreso a MIR-Praxis, donde encontraba un acierto teórico. Esta

26 Con el título "Ingresan a Praxis varios afiliados a Intransigencia”, la declaración salió publicada en los diarios de la ciudad El Plata, El Día y El Argentino los días 10 y 11 de febrero de 1959 y estaba firmada por trece personas que se declaraban miembros de la estructura orgánica de la Juventud de la UCRI con diversa jerarquía: congresales nacionales y provinciales, miembros de la Junta de Propaganda, interventores de distrito, miembros del comité local. Entre ellos, Ramón Torres Molina, Horacio Fariña, Miguel Zabala Ortíz, Alberto y Carlos Pinto, todos ellos de Derecho; Susana Dupetit de Medicina y Carlos Guerra de Ingeniería. Información extraída de: Documento MIR-Praxis, CPM-Fondo DIPBA, Mesa A, Factor Político, Legajo 49.

27 Declaración “Ingresan a Praxis varios afiliados a Intransigencia” en Documento MIR-Praxis, CPM-Fondo DIPBA, op. cit. 
organización, surgida mediando la década de 1940 y dirigida por Silvio Frondizi, es considerada una de las primeras expresiones de la "nueva izquierda" argentina, siendo su aporte teórico uno fundamental para el movimiento de ruptura y renovación ideológica que esta expresó.

Sus posiciones respecto del gobierno de la UCRI, de la Revolución Cubana, del peronismo; así como también sus críticas a los partidos clásicos de la izquierda argentina, le dieron al grupo gran prestigio en la juventud de la época. Según Horacio Tarcus, su nota central ha radicado no tanto en la extensión cuantitativa sino en sus aportes teóricos e identitarios para la formación de una nueva generación de militantes ${ }^{28}$. La importancia otorgada a la formación y el estudio, así como el alto nivel teórico de sus publicaciones e intervenciones es un dato sobresaliente de esta organización que recién se lanzó a la acción política práctica hacia 1955. Por entonces, Silvio Frondizi, Marcos Kaplan y el peruano Ricardo Napurí eran sus referentes. De acuerdo a Tarcus, MIR-Praxis fue el primer grupo de izquierda que no reconocía sus antecedentes ni en el socialismo, ni el PC, ni en trotskismo. De la misma manera, dos posiciones políticas frente a la coyuntura de fines de 1950 parecen haber sido un acierto: MIR-Praxis no apoyó al gobierno de Arturo Frondizi, contrariamente, presagió su viraje a partir de considerar caduco el lugar de las burguesías nacionales en el desarrollo de las naciones dependientes. Por otro lado, se mostró entusiasta de la Revolución Cubana desde la primera hora a razón de las estrechas relaciones de Napurí con los cubanos, y del viaje de Silvio Frondizi a la isla entre mayo y julio de 1960. Pero también, el experimento cubano vino a ratificar dos tesis centrales del MIR-Praxis: primero, el carácter obsoleto de la estrategia de las izquierdas tradicionales, cada vez más aisladas de las masas latinoamericanas y los procesos políticos del continente; segundo, y en relación a lo anterior, se confirmaba la necesidad de que las revoluciones latinoamericanas sean permanentes y socialistas, es decir, que no se detuvieran en la etapa nacional-democrática, tal como la estrategia comunista propiciaba para el continente ${ }^{29}$. Desde aquí, la proyección latinoamericana de la organización argentina fue en ascenso, al punto de que en Venezuela, Chile y Perú nuevas organizaciones armadas tomaron su nombre.

28 Tarcus Horacio, El marxismo olvidado en la Argentina: Silvio Frondizi y Milicíades Peña, Buenos Aires, El cielo por asalto, 1996. La bibliografía sobre esta organización es más bien escasa. No encontramos, además, nada concreto sobre su alcance en La Plata. Sin embargo, cabe indicar que un análisis de las principales ideas de Silvio Frondizi puede verse en Amaral, Samuel, "Silvio Frondizi y el surgimiento de la nueva izquierda", Serie Documentos de Trabajo 313, Universidad del CEMA, 2005; Lowy Michel, El marxismo en América Latina, Santiago, LOM Ediciones, 2007, pp. 44-45; Georgieff, Guillermina, Nación y revolución. Itinerarios de una controversia en Argentina (1960-1970), Buenos Aires, Prometeo, 2008, pp.130135. Una reconstrucción de la trayectoria de un grupo de MIR-Praxis que acabó en las FAR (ilustrando la idea de sus aportes a toda una generación de militancia) puede verse en el artículo de González Canosa Mora, "Los pasos perdidos. Acerca de uno de los grupos fundadores de las FAR (1960-1966)", Cuestiones de Sociología 7, 2010. Una historia de núcleo fundador de MIR-Praxis puede verse a través de la biografía de Ricardo Napurí editada en 2010.

29 Tarcus, op. cit., 346-347. Según Michael Lowy, Silvio Frondizi fue una de las raras excepciones a la hegemonía de los partidos comunistas en el pensamiento de izquierdas latinoamericano durante los años cuarenta y cincuenta. 
En la ciudad de La Plata, el núcleo dinámico de MIR-Praxis estuvo radicado en la facultad de Derecho, a la cual pertenecían más de la mitad de los y las firmantes de aquella solicitada, entre ellos, Ramón Torres Molina, Horacio Fariña y Miguel Zabala Rodríguez. En 1958, además, Silvio Frondizi había ganado el concurso de la cátedra de Derecho Político de dicha facultad convirtiéndose esta en una suerte de tribuna para el intelectual/militante. Como anunciamos, el segundo movimiento de los ex ucristas estuvo dado por el abandono de la agrupación Avanzada Reformista a mediados del año 1959. En este ámbito, dos hechos aparecieron como precipitantes de las decisiones: la reglamentación del Artículo $\mathrm{n}^{\circ} 28$ y los acuerdos firmados por el gobierno con empresas extranjeras para la exploración y explotación del petróleo ${ }^{30}$. Dos muestras claras además de la traición programática arriba anunciada. En mayo, una nota de IER enuncia las razones de la fractura con Avanzada enfatizando el hecho de que la misma ya no constituía una herramienta de lucha pues su situación de descomposición política la volvía ineficaz y en los hechos, "aliada de la reacción”. Al mismo tiempo, el foco se colocó en la no superación de su "carácter partidista", de esta manera la crítica iba dirigida también a quienes dentro de Avanzada mantenían su opinión favorable al gobierno de Arturo Frondizi. En una línea de continuidad, la "descomposición" de Avanzada aparece como el "fiel reflejo de la descomposición de los partidos burgueses y del partido oficialista en particular" 31 . Sin dudas, la UCRI y Avanzada iban a aparecer como herramientas ya caducas para quienes entre los puntos centrales de su nueva propuesta programática incluían la lucha contra el capitalismo y el imperialismo; el apoyo a toda lucha de liberación nacional realizada por movimientos y pueblos, especialmente, de América Latina; y la transformación de la estructura social argentina de acuerdo a la misma orientación ${ }^{32}$.

Ahora bien, de estas posiciones se derivaba para el nuevo grupo una nueva relación con la política estudiantil y la Reforma Universitaria. Esta no solo debía servir de puente con las luchas arriba enunciadas, también hacía falta enunciar una "política revolucionaria para la universidad" pues el reformismo había demostrado su "incapacidad como movimiento para expresar las protestas estudiantiles al carecer, como ideología de la

$30 \quad$ Al respecto, dice Ramón Torres Molina: "La primera disidencia con Avanzada fue por parte de quienes formamos Praxis en La Plata. Nos mantuvimos un tiempo en la agrupación y posteriormente, al dejar Avanzada, formamos Izquierda Estudiantil Revolucionaria, que fue expresión de Praxis en la Facultad. Había militantes en otras facultades, pero participaban de otras agrupaciones. Nuestro ingreso a Praxis fue consecuencia del contacto que manteníamos con Silvio Frondizi, profesor de Derecho Político (...) Las disidencias con el frondizismo tuvieron su origen en las políticas del gobierno, principalmente en las concesiones petroleras. Influyó también el conflicto laica-libre, pero eso no fue lo fundamental." (Entrevista realizada por la autora, 12/12/2016).

31 "Por qué nos separamos de Avanzada Reformista", agrupación IER, mayo de 1959, Archivo Personal de Ramón Torres Molina.

32 Transcribimos textualmente el tercer punto de la declaración programática: “3) Transformación cualitativa de la sociedad argentina. Liquidación de todas las formas de privilegio, origen del atraso y de la reacción en todos los planos. Planificación de la economía nacional en función de los intereses generales de la comunidad y bajo la dirección de los trabajadores. Nacionalización sin indemnización de las grandes fuentes de materias primas y de energía, de los consorcios monopolistas (...)". En: "Declaración de Principios", agrupación IER, junio de 1959, Archivo Personal de Ramón Torres Molina. 
pequeña burguesía, de bases reales de lucha"33. Como vemos, no es que la militancia en las universidades y la lucha propia de ese territorio debía abandonarse, sino que la misma debía estar orientada por objetivos distintos, más radicalizados que los clásicos.

Si bien en las facultades de Medicina y Humanidades también se llegó a tener una presencia mínima, el centro del grupo platense de MIR-Praxis estuvo en Derecho y en IER. En sus inicios, dicha agrupación contó con alrededor de diez integrantes, número que, para la segunda parte de 1959, llegó a duplicarse. Las primeras actividades que realizó tuvieron lugar entre fines de 1958 y comienzos de 1959, bajo la forma de charlas en las facultades de Medicina, Derecho y Humanidades, con los dirigentes Ricardo Napurí, Marcos Kaplan y Eugenio Werden. Uno de los temas centrales y repetido de estas actividades fue, como es de esperarse, el de la Revolución Cubana, cuestión además bien conocida por Napurí. De esta manera nos encontramos, por un lado, con un espacio que intentaba asentarse en la UNLP mediante actividades que le permitieran sumar y consolidar militancia "frustrada". Por otro, con un movimiento o pasaje de la adhesión o afiliación a la UCRI hacia una opción sin dudas más radical, acompañado de intensa formación teórica y discusiones sobre acontecimientos clave de la escena política.

\section{El ingreso a Palabra Obrera: el trotskismo, el otro espacio político para "los frustrados"}

1959 parece ser el año de los movimientos. Finalizando el mes de abril, un aviso en el periódico El Argentino anunció el surgimiento del Centro de Estudios Sociales "Primero de Mayo", con una primera reunión en la famosa Casa de los sindicatos de calle 57. El mismo no pasa desapercibido pues lo integran casi una decena de dirigentes estudiantiles reformistas integrantes de Avanzada Reformista-Derecho y ARICE-Económicas, principalmente, y con importantes lugares en las mesas dirigenciales de FULP y FUA. Los nombres de Alejandro Dabat y Carlos Schiavello, son entre ellos, los que más sobresalen ${ }^{34}$. La conformación del nuevo espacio nos ayuda a ilustrar la crisis ideológica de los jóvenes reformistas frondizistas. Una serie de elementos deja ver la declaración inicial del espacio, el primero de ellos, está dado por la situación de "desconcierto" y "desesperanza" que, en sus palabras, atravesaba a los núcleos y sectores "más avanzados" de la juventud reformista. Frente a tal situación de incertezas, los ex frondizistas encontraban que el reformismo como marco ideológico y político ya no servía, así como tampoco las "tradicionales interpretaciones liberales", caracterizadas como insuficientes para ofrecer un

33 Se enuncian a continuación quince puntos para un programa de la izquierda revolucionaria en la universidad, que incluyen: superación de las limitaciones que constituye el régimen secundario para el acceso a la clase obrera a la universidad; salarios de estudiante; bonificación considerable al obrero o empleado que estudien; entrega gratuita de los materiales de trabajo y de los libros necesarios, entre otros. Ídem.

34 Algunos de los otros integrantes eran: Heriberto Zardini (de ARICE-Económicas), Arturo Gómez (de Avanzada Reformista-Derecho), Rafael Lombardi (también de Avanzada Reformista-Derecho e integrante de la Junta de FULP durante 1958), Eduardo Urretavizcaya (secretario de FUA por la FULP durante la presidencia del platense Omar Patti en 1958), Raúl Reig de Ingeniería, Hugo Santilli de Medicina, Fernando Maturano, Ernesto Gorilis, entre otros (El Argentino, 28/04/1959). 
“programa de lucha antiimperialista y de liberación nacional”. El estado de situación estaba claro (la "desesperanza" y la ausencia de marcos teóricos y programáticos acordes) así como también las tareas impuestas por la realidad política. Entre ambos polos, el Centro se proponía trabajar en la "corrección teórica" y el "esclarecimiento doctrinario" de los jóvenes reformistas para asumir con fuerza y conciencia su responsabilidad en la "búsqueda de un camino revolucionario conscientemente fundado que permita al estudiantado reformista jugar el papel que esta hora universal de liberación de las masas oprimidas exige $(\ldots) " 35$.

Dadas las cosas, estas palabras vislumbran un balance del gobierno frondizista, una nueva lectura de la realidad argentina, así como también una nueva propuesta de acción, para los reformistas y los jóvenes comprometidos. Dos factores se constituían como los datos más sobresalientes de la etapa argentina abierta en 1958: la "agudización de la penetración imperialista" y el "papel dirigente de la clase obrera", al frente de las fuerzas populares que resisten ese avance. Considerada la contradicción principal del momento, se entendía que los estudiantes debían "sumar su militancia a los esfuerzos de las columnas populares" mediante un programa de liberación nacional y lucha antiimperialista, lo que arriba caracterizamos también como "camino revolucionario" "36, evidentemente, única posibilidad para salir de la situación de frustración y desconcierto en que las acciones del gobierno de Arturo Frondizi dejó a quienes los habían apoyado.

Hemos reparado en este caso no solo porque fueran dirigentes reformistas importantes quienes lo impulsaron, también porque nos ayuda a describir y certificar lo dicho arriba, esto es, el abandono de las filas del frondizismo de una parte de los cuadros reformistas y la opción por caminos radicales de izquierda. Hacia mayo de 1959, ese mismo núcleo estudiantil acabó ingresando a la organización trotskista Palabra Obrera, con trayectoria de larga data en La Plata, Berisso y Ensenada.

Una breve historización de Palabra Obrera nos remite, al menos, a los fines de la década de 1950, momento del surgimiento del Movimiento de Agrupaciones Obreras (MAO). Liderada por Nahuel Moreno (seudónimo de Hugo Bressano) el MAO surgió en 1957 en el marco del VI Congreso del Partido Obrero Revolucionario. La nueva organización fue producto de la decisión de ampliar las estructuras partidarias para permitir la incorporación de dirigentes sindicales afines a la línea del partido, aunque no orgánicos e incluso también, peronistas. Por ello, y tal como indican los escasos estudios sobre la organización $^{37}$, el MAO se entiende como una corriente sindical que tenía entre sus objetivos luchar contra la "Revolución Libertadora" y agrupar activistas gremiales bajo una orientación clasista. La experiencia del MAO llevó a los trotskistas a replantearse la estrategia frente al movimiento peronista a partir del debate sobre si dicha tendencia gremial clasista debía estructurarse por dentro o por fuera de las organizaciones gremiales

\footnotetext{
35 Idem.

$36 \quad$ Idem.

37 González Ernesto (comp.), El trotskismo obrero e internacionalista en Argentina, Buenos Aires, Antídoto, 1996, Tomo 2, pp. 163-171; Carnovale Vera, Los combatientes, Buenos Aires, Siglo XXI, 2011, pp. 42-47; Camarero Hernán, "Una experiencia de la izquierda en el movimiento obrero", Razón y Revolución 3, invierno de 1997, reedición electrónica.
} 
peronistas. De aquí se deriva la más conocida táctica de "entrismo" en el peronismo obrero, con la cual se identifica rápidamente a la organización. De acuerdo a la obra citada de Hernán Camarero, el "entrismo" consistía en reconocerse públicamente como peronista con el objetivo de lograr un mayor acercamiento de los trabajadores y espacios que adherían a él. En julio de 1957 comenzó editarse Palabra Obrera, publicación del MAO dirigida por Ángel "Vasco" Bengochea, que alcanzó una importante popularidad y acabó dando el nombre a la organización partidaria. Bengochea era dirigente partidario de La Plata y Berisso. Más importante que la primera, la segunda localidad, de fuerte historia obrera, era donde el MAO tenía uno de sus dos locales públicos y un importante papel en la creación de agrupaciones fabriles de base que convocaron a decenas de trabajadores peronistas ${ }^{38}$.

Ernesto González en su clásico trabajo sobre el trotskismo en Argentina da cuenta del proceso por el cual aquella decena de militantes reformistas acabó en Palabra Obrera. Para el ex militante, las posiciones intransigentes hacia el gobierno mantenidas por el partido fueron las que le permitieron, durante 1958 y a la luz de los conflictos derivados del tema petrolero y universitario, "ganar" a varios de los principales activistas estudiantiles ya en proceso de alejamiento del frondizismo. Por entonces, el trabajo universitario más importante de Palabra Obrera estaba concentrado en la UBA, con agrupaciones en las facultades de Farmacia, Derecho, Económicas y Medicina y dirigentes como Lázaro Feldman y Hugo Kiernan. Al tiempo, se mantenían algunos pocos contactos en La Plata y Bahía Blanca. Esto cambió a fines de 1958: si bien la participación de PO en los conflictos por la Laica o Libre fue casi nula, la misma logró acumular a partir de las consecuencias, esto es, la derrota y la crisis del frondizismo.

En la UNLP, Carlos Schiavello de Ingeniería aparece como uno de los primeros en ingresar a la organización que logró luego "arrastrar" al grupo restante ${ }^{39}$. Esto es lo que ocurre durante los primeros meses de 1959, mientras las agrupaciones del frondizismo "explotaban" y sus dirigentes se encontraban en una especie de situación de "disponibilidad política". Por entonces, la existencia orgánica de Palabra Obrera en la universidad platense era prácticamente inexistente, "embrionaria" aunque estaba en marcha un trabajo de captación del grupo de Derecho a punto de romper con Avanzada y el frondizismo. De acuerdo a quienes "seguían" al grupo, este se encontraba en una situación de "falta de línea

38 A comienzos de los años sesenta, una fracción de PO, liderada por el Vasco Bengochea conforma las Fuerzas Armadas para la Revolución Nacional, experiencia abortada en julio de 1964 tras un episodio fatal: la explosión del piso donde estaba reunida buena parte de la organización. Allí se encontraban el otrora presidente de FULP, Carlos Schiavello y los ex militantes reformistas platenses Raúl Reig y Hugo Santilli. Ver: Nicanoff Sergio y Castellano Axel, Las primeras experiencias guerrilleras en la Argentina. La historia del Vasco Bengochea y las FARN, Buenos Aires, Ediciones del CCC, 2006, p. 23.

39 Dice textualmente González: "Por ejemplo a Carlos Schiavello, de la Facultad de Ingeniería y presidente de la Federación Universitaria (FULP). El "Negro" Schiavello, durante el proceso que había llevado a la formación de las 62 Organizaciones, fue el primer cuadro estudiantil en ligarse a la nueva vanguardia obrera, facilitando la realización de sus plenarios en los jardines de la Universidad, en momentos de gran represión. Producto de esa ligazón, Palabra Obrera incorporó también a otros militantes estudiantiles que luego se transformaron en importantes dirigentes y cuadros del partido." González Ernesto, op.cit, p. 246. 
y aislamiento político", otras palabras para describir aquel desconcierto enunciado antes ${ }^{40}$. No se entiende la creación del Centro de Estudios Sociales "Primero de Mayo" sin este marco. El mismo aparece como una suerte de espacio de transición entre la crisis arriba descripta y el ingreso a Palabra Obrera, la decisión tomada al fin para realizar aquel camino revolucionario. De hecho, en las primeras actividades del Centro participaron militantes de la organización trotskista y Amanda Peralta, encargada por Palabra Obrera de seguir al grupo, que llegó a ser su secretaria de Organización ${ }^{41}$.

Entonces, podemos afirmar que el Centro de Estudios Sociales "Primero de Mayo" se constituyó como un espacio de transición en un proceso que va desde el frondizismo y la militancia universitaria reformista (cuya importancia aún no se niega, aunque sí se indica la necesidad de una renovación ideológica) hacia la militancia netamente partidaria (que sí acabará negando la universitaria). Es decir, una suerte de estadio intermedio que se proponía reorientar ideológicamente al reformismo ligándolo con las luchas obreras.

Luego del ingreso colectivo a PO, la opción de sostener la militancia universitaria va a verse modificada, de acuerdo a la estrategia más general de la organización. La orientación del partido para esta nueva camada de jóvenes estuvo dada por la "proletarización", es decir, el pasaje al trabajo en las fábricas, la militancia en las células obreras y/o el aporte a la difusión de la línea del partido en los barrios obreros. Como es esperable, la mayor parte de los miembros del grupo trasladó su militancia a Berisso y Ensenada, fundamentalmente en los frigoríficos de la primera y en el local de la calle Nueva York que el partido tenía allíi ${ }^{42}$. A modo de ilustración puede mencionarse el caso de Hugo Santilli, enviado una vez recibido a fines de 1960 a realizar tareas a Tucumán, razón por la cual se convertirá en el médico de la Federación Obrera de Trabajadores de Ingenios Azucareros y en uno de los importantes lazos entre la organización santiagueña Frente Revolucionario Indoamericano y Popular (FRIP) y Palabra Obrera ${ }^{43}$.

$40 \quad$ Ambas citas pertenecen a: "Informe sobre La Plata a la dirección del equipo estudiantil", firmado por Bela con fecha en 24/04/1959, Archivo de la Fundación Pluma. En este documento se observa que uno de los contactos más importantes dentro del grupo de Derecho es Alejandro Dabat, quien además habría invitado a sus contactos de PO a asistir a la reunión inicial del Centro de Estudios Sociales, cuestión que se recomienda explícitamente en el informe. También se informa que este contaría con alrededor de 25 integrantes.

41 "Informe de La Plata, preparado por la compañera Amanda" con fecha en 29/05/1959, Archivo de la Fundación Pluma. El mismo está realizado por Amanda Peralta, mencionada en el informe antes citado como contacto clave.

42 Dice, por ejemplo, Arturo Gómez, ex integrante de Avanzada Reformista: "Todos nosotros, que éramos dirigentes estudiantiles, dejamos de militar en la universidad y nos volcamos al movimiento obrero. Ahora [1974], viéndolo quince años después, es fácil decir que podríamos haber combinado la actividad, o no haber sido tan tajantes en dejar la actividad estudiantil; pero me parece que no fue un error, porque logramos hacer cuadros del movimiento obrero.” en González Ernesto, op.cit., p. 248.

43 Una reconstrucción de la trayectoria de Santilli a partir de los testimonios de sus familiares, ver en Nicanoff y Castellano, op.cit., p. 47 y 96-97. La bibliografía resalta también un elemento sobre el que cabe profundizar: la relación entre la militancia estudiantil platense de PO y la agrupación MIECE de los Santucho (personificada esta entre Rafael Lombardi, militante de PO, y Raúl Echezarreta, santiagueño del FRIP radicado en Buenos Aires). Ver: Pozzi Pablo, "El Norte revolucionario e indoamericanista antes del PRT-ERP: el FRIP”, Voces Recobradas 13, julio de 2002, pp. 25-39, p.32. 
Hacia 1960 la orientación partidaria es revertida y la militancia de PO vuelve a la universidad aunque con organizaciones mínimas y de escasa militancia, como el Frente de Estudiantes de Derecho o el de Ingeniería. Sin dudas, la crisis múltiple del espacio frondizista y la desaparición de buena parte de sus cuadros se reflejó en la pérdida de poder de la corriente de izquierdas dentro del reformismo que quedó en manos de las agrupaciones y la militancia comunista. Durante 1959 y 1960, los principales referentes del reformismo de izquierdas pasaron de ser militantes universitarios identificados con el radicalismo intransigente a serlo con el PC y con organizaciones de la "nueva izquierda" (estas, de reciente aparición y menores que el histórico partido) como MIR-Praxis y el Socialismo Argentino. A fines de 1958, Carlos Schiavello y Alejandro Dabat abandonan la presidencia de FULP, para quedar en su lugar a Juan Carlos Delorenzo y Enzo Bard, ex frondizista el primero, comunista el segundo. En marzo de 1959, Adolfo "Otto" Sturzenegger y Julio Godio asumen como presidente y como secretario general de la FULP. No hay dudas de la organicidad comunista del segundo; en cuanto al primero, si bien siempre se mantuvo independiente representa lo antes dicho pues su trayectoria va desde la adhesión al frondizismo hacia una más bien filo comunista ${ }^{44}$; entre 1960 y 1961, fue Rafael Tancredi del Socialismo Argentino quien asumió dicho lugar. De aquí en más, la dirigencia reformista platense entra en un período de inestabilidad que se cerrará hacia 1962, con el marcado predominio de aquel reformismo anticomunista y más bien "liberal".

\section{Palabras finales}

Se intentó reconstruir en estas páginas el impacto de la llamada "traición Frondizi" sobre la juventud reformista de la ciudad de La Plata atendiendo en particular, a los casos de quienes optaron por caminos radicalizados. Sin lugar a dudas, este es un contexto clave de la historia argentina, son estos años, como vimos, cargados de "frustraciones" y desplazamientos políticos en un movimiento estudiantil expectante por lo que iría a suceder en el país y en las universidades. Son años también de renovación ideológica para una izquierda que, al calor de la Resistencia Peronista y la Revolución Cubana, modificará sus visiones estratégicas para la lucha revolucionaria en el país.

$44 \quad$ Dice el mismo Godio: "Fui integrante de la FULP y después presidente. Eso debe haber sido, en la dirección de la FULP desde el 1958 hasta el 1962 (...) En esos años de militancia universitaria yo formaba parte de la conducción de la Federación Juvenil Comunista (FJC). Tuve mucha actividad ahí, hasta el año 1966." en Del Bono Andrea y Fernández B. Leticia "Una vida y una obra dedicadas al estudio del sindicalismo argentino y latinoamericano: Entrevista a Julio Godio”, Cuestiones de Sociología 7, 2011, pp. 236-237. Luego, Adolfo Sturzenegger nos dice sobre su trayectoria: "Yo empecé a militar a comienzos de 1956, iniciando mi tercer año en la carrera. La agrupación se llamó ARICE y el grupo que la formó inicialmente fue uno frondizista. Yo era independiente políticamente, no estaba afiliado al radicalismo pero me uní a ellos. En 1956 estaba la "Revolución Libertadora", Fondizi entra al gobierno en 1958, ya antes era una figura política importante en el ámbito universitario (...) Eramos un grupo frondizista que en aquel momento éramos muy partidarios de la Revolución Cubana, sobre todo en sus comienzos. Pero el gran debate que vivimos en ARICE y en la FULP fue el de la Laica o Libre." (Entrevista realidad por la autora, 7/03/2016). 
Una primera parte de este trabajo estuvo dedicada a reparar en el proceso de cambios y renovaciones que se abre en el reformismo platense en 1956/1957. Este tuvo como nota central no solo cambios en el mapa político de la FULP sino también la emergencia de lecturas cada vez más críticas sobre el gobierno de la Revolución Libertadora que empalmaron con el ascenso político de la fracción Intransigente de la UCR, organización con fuerte peso en el reformismo de la UNLP. El año 1958 es nuestro momento clave. Más en particular lo son los conflictos suscitados en torno al Artículo $\mathrm{n}^{\circ} 28$ y a la Batalla del Petróleo. Creemos que las movilizaciones de 1958, con una masividad de carácter inédito, marcan un parteaguas en la historia de la militancia reformista de La Plata: comienzan aquí desplazamientos, fracturas y un proceso de radicalización política en algunos sectores de esa militancia, que son el germen del amplio proceso de contestación y protesta social que marcó la década siguiente. Tanto el caso del grupo que acaba en Palabra Obrera como el que forma MIR-Praxis comparten una serie de frustraciones, acompañadas de nuevas certezas. El aprendizaje que deja la experiencia desarrollista lleva a estos jóvenes a posiciones anticapitalistas y antiimperialistas que luego Cuba viene a verificar. En este marco, tanto los principios de la democracia liberal como los de la Reforma Universitaria se comprenden casi como obsoletos.

Se entiende desde aquí que no es mera anécdota el hecho de que buena parte de los nombres mencionados los encontramos varios años más tarde ensayando otras vías y métodos políticos. Incluso, como se sabe, PO y MIR-Praxis acabaron en importantes experiencias de izquierda de los años setenta: en 1965 confluyó en el Partido Revolucionario de los Trabajadores, una de las organizaciones armadas más grandes de los años setenta; no pocos militantes de MIR-Praxis acaban siendo dirigentes de organizaciones como las Fuerzas Armadas Revolucionarias o las Fuerzas Armadas de Liberación. Nuestro esfuerzo ha estado colocado en aportar a una mirada de "largo plazo" para comprender cabalmente la politización de la sociedad argentina reciente. En el campo de estudios sobre el período, el fuerte protagonismo otorgado a las organizaciones armadas de los años setenta ha conllevado una escasa atención sobre los tempranos años sesenta, los cuales nos permiten observar debates, trayectorias y procesos (colectivos e individuales) que precedieron a la opción armada, que la englobaron o que incluso la explican. Como afirma Cristina Tortti, este tipo de perspectiva histórica acarrea el efecto de oscurecer procesos y trayectorias militantes (previas) e invisibilizar buena parte de los actores que dieron densidad al ciclo de protesta y oposición. Es decir, no contribuye a comprender de forma satisfactoria las formas de protestar y hacer política que distintos sectores de la sociedad ensayaron antes o durante de optar por las $\operatorname{armas}^{45}$. La reconstrucción de aquellos desplazamientos tempranos en el mapa del reformismo universitario nos permitirá comprender procesos posteriores de forma algo más acabada, esto es, en un largo plazo y como producto de la acumulación de ensayos, errores y experiencias. 


\section{Bibliografía}

- Altamirano Carlos, Peronismo y cultura de izquierda, Buenos Aires, Temas Grupo Editorial, 2001. - Amaral, Samuel, "Silvio Frondizi y el surgimiento de la nueva izquierda", Serie Documentos de Trabajo 313, Universidad del CEMA, 2005.

- Belini Claudio, "Reestructurando el estado industrial: El caso de la privatización de la DiNIE, 1955-1962”, Desarrollo Económico 181, abril-junio 2006, pp. 89-116.

- Belini Claudio y Korol Juan Carlos, Historia económica de la Argentina en el siglo XX, Buenos Aires, Siglo XXI, 2012.

- Califa Juan, Reforma y Revolución. La radicalización política del movimiento estudiantil de la UBA 1943-1966, Buenos Aires, Eudeba, 2014.

- Camarero Hernán, "Una experiencia de la izquierda en el movimiento obrero", Razón y Revolución 3, invierno de 1997.

- Carnovale Vera, Los combatientes. Historia del PRT-ERP, Buenos Aires, Siglo XXI, 2011.

- Ferrero Roberto, Historia crítica del movimiento estudiantil de Córdoba. Tomo III (1955-1973), Alción, Córdoba, 2009.

- González Ernesto (coord.), El trotskismo obrero e internacionalista en Argentina, Buenos Aires, Antídoto, 1996.

- González Canosa Mora, "Los pasos perdidos. Acerca de uno de los grupos fundadores de las FAR (1960-1966)", Cuestiones de Sociología 7, 2010.

- Gordillo Mónica (2003): "Protesta, rebelión y movilización: de la resistencia a la lucha armada; 1955-1976" en James D. (coord.) Violencia proscripción y autoritarismo. Tomo VIII, Nueva Historia Argentina. Sudamericana, Buenos Aires.

- James Daniel, Resistencia e integración: el peronismo y la clase trabajadora argentina: 19461976, Buenos Aires, Siglo XXI, 2010.

- Kleiner Bernardo, 20 años de movimiento estudiantil reformista, Buenos Aires, Platina, 1964.

- Löwy Michael, El marxismo en América Latina, Santiago de Chile, LOM Ediciones, 2007.

- Manzano Valeria, "Las batallas de los "laicos": movilización estudiantil en Buenos Aires, 1958" en Boletín del Instituto de Historia Argentina y Americana "Dr. E. Ravignani” 31, 2006, pp. 123150.

- Napurí Ricardo, Pensar América Latina. Crónicas autobiográficas de un militante revolucionario, Buenos Aires, Herramienta, 2010.

- Nicanoff Sergio y Castellano Axel, Las primeras experiencias guerrilleras en la Argentina. La historia del Vasco Bengochea y las Fuerzas Armadas para la Revolución Nacional, Buenos Aires, Ediciones del CCC, 2006.

- O’Donnell Guillermo, “Estado y alianzas en la política argentina 1956-1976” en Desarrollo Económico 64, Buenos Aires, 1977, pp. 523-554.

- Pis Diez Nayla, "Es hora de jugar la Universidad. Una reconstrucción de las luchas reformistas en las calles platenses durante la Laica o Libre”, Conflicto Social 15, 2016, pp. 130-157.

"Compañero trabajador, no falte! El movimiento reformista de La Plata y la unidad obrero-estudiantil en los tempranos sesenta: acciones por una vieja bandera", Revista de la Red de Intercátedras de Historia de América Latina Contemporánea 6, 2017, pp. 99-114.

- Pontoriero Esteban, "Estado de excepción y contrainsurgencia: el plan Conintes y la militarización de la seguridad interna en la Argentina (1958-1962)", Contenciosa 4, primer semestre de 2015.

- Portantiero Juan Carlos, "Economía y política en la crisis argentina (1958-1973)", en Ansaldi y Moreno (comps.) Estado y Sociedad en el Pensamiento nacional, Buenos Aires, Cántaro, 1989, pp. 301-346. 
- Pozzi Pablo, "El Norte revolucionario e indoamericanista antes del PRT-ERP: el FRIP", Voces Recobradas 13, julio de 2002, pp. 25-39.

- Pucciarelli Alfredo, "Los dilemas irresueltos en la historia reciente de la Argentina", en El Taller 4, Buenos Aires, 1997, pp. 82-121.

- Schneider Alejandro, Los compañeros: izquierda, trabajadores y peronismo en la Argentina, 19551973, Buenos Aires, Imago Mundi, 2005.

- Sigal Silvia, Intelectuales y poder en la década del sesenta, Buenos Aires, Puntosur, 1991.

- Spinelli María Estela, Los vencedores vencidos. El antiperonismo y la "revolución libertadora", Buenos Aires, Biblos, 2005.

- Tarcus Horacio, El marxismo olvidado en la Argentina: Silvio Frondizi y Milicíades Peña, Buenos Aires, El cielo por asalto, 1996.

- Tortti María Cristina, "Debates y rupturas en los Partidos Comunista y Socialista durante el frondizismo", Prisma 6, 2002, pp. 265-274.

"La nueva izquierda argentina. La cuestión del peronismo y el tema de la revolución" en Tortti (dir.) La nueva izquierda argentina (1955-1976), Socialismo, peronismo y revolución, Rosario, Prohistoria, 2014, pp. 15-33.

\section{Documentos citados}

- Diario El Argentino (La Plata, 1955-1962)

- Documento MIR-Praxis (1959-1961), Mesa A, Factor Político, Leg. 49. Comisión Provincial por la Memoria - Fondo DIPBA, División Central de Documentación, Registro y Archivo.

- Documento Movimiento de solidaridad obrero estudiantil, Mesa A, Carpeta Estudiantil, Leg. 22. Comisión Provincial por la Memoria - Fondo DIPBA, División Central de Documentación, Registro y Archivo.

- "Por qué nos separamos de Avanzada Reformista", agrupación IER, mayo de 1959, Archivo Personal de Ramón Torres Molina

- "Declaración de Principios", agrupación IER, junio de 1959, Archivo Personal de Ramón Torres Molina.

- "Informe sobre La Plata a la dirección del equipo estudiantil", firmado por Bela con fecha en 24/04/1959, Archivo de la Fundación Pluma.

- "Informe de La Plata, preparado por la compañera Amanda" con fecha en 29/05/1959, Archivo de la Fundación Pluma.

\section{Entrevistas}

- Del Bono Andrea y Fernández Berdaguer Leticia, "Una vida y una obra dedicadas al estudio del sindicalismo argentino y latinoamericano: Entrevista a Julio Godio", Cuestiones de Sociología 7, 2011.

- Toer Mario (1988): El movimiento estudiantil de Perón a Alfonsín, CEAL, Buenos Aires.

- Entrevista realidad por la autora a Adolfo Sturzzenegger, La Plata, 7/03/2016.

- Entrevista realizada por la autora a Ramón Torres Molina, La Plata, 12/12/2016.

- Entrevista realizada por la autora a Héctor A. Palacios, La Plata, 30/03/2017. 